\title{
Emotion-based IS support for Customer-Salesperson Interaction
}

\author{
Michael Meyer \\ TU Braunschweig \\ m.meyer@tu-bs.de
}

\author{
Dominik Siemon \\ TU Braunschweig \\ d.siemon@tu-bs.de
}

\author{
Susanne Robra-Bissantz \\ TU Braunschweig \\ s.robra-bissantz@tu-bs.de
}

\begin{abstract}
While e-commerce is experiencing increasing sales, stationary retail is losing customers. One way to address this problem is to digitally support the advantages of stationary retail and offer new services to the customer. Following a Design Science Research approach, we present two consecutive design cycles in which we propose an emotion-based information system (IS) to support the interaction between customers and sales personnel. Design cycle 1 focuses on generating design knowledge in form of design guidelines, while design cycle 2 aims to exert them into a specific expository instantiation in order to evaluate them. In an increasingly digital world with changing customers, this contribution shows that emotions might be a key element in the design of valuable IS-supported interactions. Hereby we address the identified lack of literature on emotion-based ISs in the stationary retail sector.
\end{abstract}

\section{Introduction}

The digital transformation manifests itself as a technological and social change process. At the heart of this change lies the shift from analogue to digital and from offline to online [25]. The advancing digitalization ensures high sales in e-commerce, but simultaneously poses challenges to stationary retail [16]. However, this change is also linked to the creation of new values and will provide opportunities for the development of new digital products and services for customers in stationary retail [32]. New personalized services can be built upon situation- and customer-centric information [34]. It turns out that customer behavior cannot be explained solely by considering rational aspects [41]. Inner states, such as emotions, can provide valuable insights into the specific situation and needs of the customer [10]. Emotions play an important role in a person's life, as they influence thinking, acting, communication and interaction [13]. In stationary retail, emotions strongly influence customer behavior and satisfaction [17]. A crucial intersection between the customer and the store is the sales personnel [45]. The way in which the sales personnel interacts with the customer is decisive for the customer's perception of the service [26]. Furthermore, this perception of the service encounter significantly correlates with the emotions felt by the customer [49]. An interaction creates a connection between the sales personnel and the customer within a common interaction space [23]. Within this space, interactions can take place that contribute to a mutual value creation [27]. The customer has the possibility to explain certain needs, while the sales personnel is able to counteract with specific services [56]. However, the mere existence of an interaction is not enough to ensure value creation [23]. An interaction characterized by a lack of quality will have negative effects on the mutual value creation [24]. Therefore, an unfitting interaction between the sales personnel and the customer negatively affects customer satisfaction and the well-being of the sales personnel [30]. To ensure that customers experience a pleasant and valuable visit in the store, we propose an IS to support the interaction between customers and sales personnel. To achieve this, we utilize the emotional situation of the customer. Expert interviews show that the correct assessment of the customers' emotional situation can be difficult (see table 1). Here, the support with an emotion-based IS is a promising approach to improve the experience and intensify the interaction by better understanding what customers need. ISs are capable of enhancing existing interactions as well as creating new opportunities for the interaction between actors $[14,38,62]$. There is research on the importance of emotions in interactions, especially between customer and sales personnel (see section 2.2) [45, 49, 50]. In addition, research has been done regarding the reciprocal influence of emotion on IS usage behavior as well as different IS-based approaches to recognize emotion $[5,15,53]$. Furthermore, ISs have proven to be an important component to support stationary retail in creating new values $[38,58,60]$. However, there is a lack of emotion-based ISs that support the interaction between customer and sales personnel. The aim of this research is to develop design knowledge for the design and development of an emotion-based IS for stationary retail. Our research follows the Design Science Research (DSR) paradigm [36] and in particular the General Methodology of Design Science Research [70]. We present the findings 
of two consecutive design cycles that include an interface prototype (cycle 1) and an instantiation (cycle 2 ). Both cycles provide valuable insights into the design and development of emotion-based ISs. Thereby we address the research question: How should an emotionbased IS be designed to support customer-salesperson interaction? The paper is structured as follows: First, the theoretical background regarding the digital transformation in retail and the importance of customer emotions is given. Next, the methodology and the design cycles are explained followed by descriptions of the development and evaluation of the two artifacts. The article ends with a discussion and an outlook.

\section{Theoretical Background}

\subsection{Digital Transformation in Retail}

The current difficulties in stationary retail are mainly caused by the digital transformation [32]. In this context, a declining customer frequency and correspondingly stagnating sales are showing up [33, 69]. This aspect is supported by the fact that $67 \%$ of millennials and $56 \%$ of the generation $\mathrm{X}$ prefer to shop online [7]. The continuing growth of e-commerce makes it essential for stationary retailers to rethink their strategies in order to meet the new conditions $[8,16]$. More than three out of five customers say that digital technologies have improved their shopping experience [55]. The modern customer is better informed and expects a more personalized and situation-based shopping experience [57]. Smartphones enable customers to access the Internet regardless of time and place [21]. This leads to a change in customer behavior and expectations [68]. This new digital retail situation offers many threads, but also numerous opportunities [34]. Stationary retail has typical business advantages and disadvantages. Due to physical limitations, stationary retail cannot offer the same range of products and services as e-commerce. Furthermore, there are disadvantages in terms of availability due to opening hours. In comparison, a purchase via a digital channel can be completed at any time and from anywhere [1]. The advantage stationary retail still has, is the qualification of the sales personnel and the resulting customer advisory service which can be offered [58]. The possibility of social interaction with the sales personnel turns out to be one of the main advantages [31]. The positive consequences of a successful interaction between the sales personnel and the customer can provide value for both actors [24, 28]. This may result in increased trust, a stronger bond and improved comfort in future interactions [29]. In order to support stationary retail and to reinforce its position towards the growing e-commerce, this contribution focuses on further expanding the existing strengths of stationary retail.

\subsection{Customer Emotions in Retail}

Emotions influence how people behave, think, communicate and interact $[10,13,46]$. Various researchers of different disciplines already defined emotions with varying results [43, 67]. The term is closely related to the terms feeling, mood and affect [19], which are often used synonymously. In this contribution we will use the term emotion or emotional situation [2]. An emotion is the result of the human body's reaction to a stimulus that occurs, such as an event or a thought of certain relevance [10]. Emotions lead to high mental activities, are perceived as positive or negative [13] and can be collected and illustrated with various models [40, 47, 63, 66]. Self-assessment is an established method to determine the current emotional situation of a person [6, 9]. With regard to the field of application of this article, the emotional situation of the customer is of particular importance. The sales personnel acts as a critical link between the store and the customer and therefore has a strong influence on the customer's emotions [45, 65], as there are significant correlations between customer emotions, behavior and satisfaction [12, 17, 48]. In order to establish a sustainable customer relationship, an environment must be created in which the customer feels comfortable [20, 45]. The most common positive and negative emotions that occur in retail are happiness and delight as well as anger and anxiety. Positive emotions are caused by a friendly and pleasant behavior of the sales personnel as well as the negotiation of good prices [50]. Furthermore, a successful interaction between the sales personnel and the customer evokes positive emotions because social needs are met [45]. Customers with positive emotions show higher satisfaction and improved loyalty [12, 72]. Negative emotions on the other hand reduce customer satisfaction, which can lead to cancellation of purchases and a lasting damage to the customer relationship [50, 59]. This may also result in customers avoiding the company, its products and services as well as its employees in the future [22, 37]. Negative emotions occur especially when customers are treated rudely or when they are unsure which product to buy or whether they should by it in the first place [50]. Given the effects of positive and negative emotions on the interaction between the customer and sales personnel, positive emotions should be strengthened and negative emotions should be transformed into positive ones. The aim of this contribution is to generate specific design knowledge based on emotions in order to provide IS support for stationary retail. 


\section{Methodology}

We base our research project on the systematic and iterative DSR paradigm proposed by Hevner et al. (2004) that combines behavioral science and designoriented research and adds rigor as well as theory into the design of artifacts [36]. Hevner et al. state that in order to create design knowledge, the development, demonstration, justification and evaluation of an artifact is important. This process involves the derivation of business needs from people, organizations and technology that provide the relevance for the construction of the artifact. A knowledge base with relevant foundations and methodologies is not only important for the construction of the artifact, but also for the evaluation and justification of its applicability. Our objective is to contribute design knowledge to address an emotion-based IS to support the interaction between customers and sales personnel. This covers knowledge on how emotion-based ISs can be designed, including expository instantiations as representations of the design knowledge for purposes of testing. We follow a model for comprehensive DSR projects that involve multiple design steps (awareness of problem, suggestion, development, evaluation and conclusion) [39, 70]. Our DSR process encompasses two consecutive design cycles that involve the design and evaluation of an interface prototype and the design and development of an instantiation. The development and subsequent evaluation of the interface prototype lead to results that went into the development and further refinement of the following design cycle (see Figure 1). While design cycle 1 focusses on generating design knowledge in form of design guidelines, the subsequent second design cycle (cycle 2) aims to exert them into a specific expository instantiation in order to evaluate them. A substantial part of an emotion-based IS are emotionreaction guidelines, that provide information on how sales personnel should react and behave towards certain customer emotions. Since these reactions and actions highly depend on the use case, scenario, culture and other circumstances, they need to be designed and evaluated specifically for each use case. The development of such emotion-reaction guidelines therefore requires further research and development and is not an objective of this DSR project.

\section{Interface prototype (Cycle 1)}

\subsection{Interface Design}

In the first design cycle, we created an interface capable of capturing the emotional situation of customers. The interface design is based on the wellestablished Circumplex Model of Affect (CMoA) [66]. The CMoA classifies a variety of emotions using the two dimensions valence and arousal. The valence dimension indicates whether an emotion is positive or negative and the arousal dimension represents the degree of activation from low to high. The basic assumption of the model is that all emotions can be traced back to a certain combination of valence and arousal. It has already been shown that the CMoA can be used as a suitable interface for the input of emotions
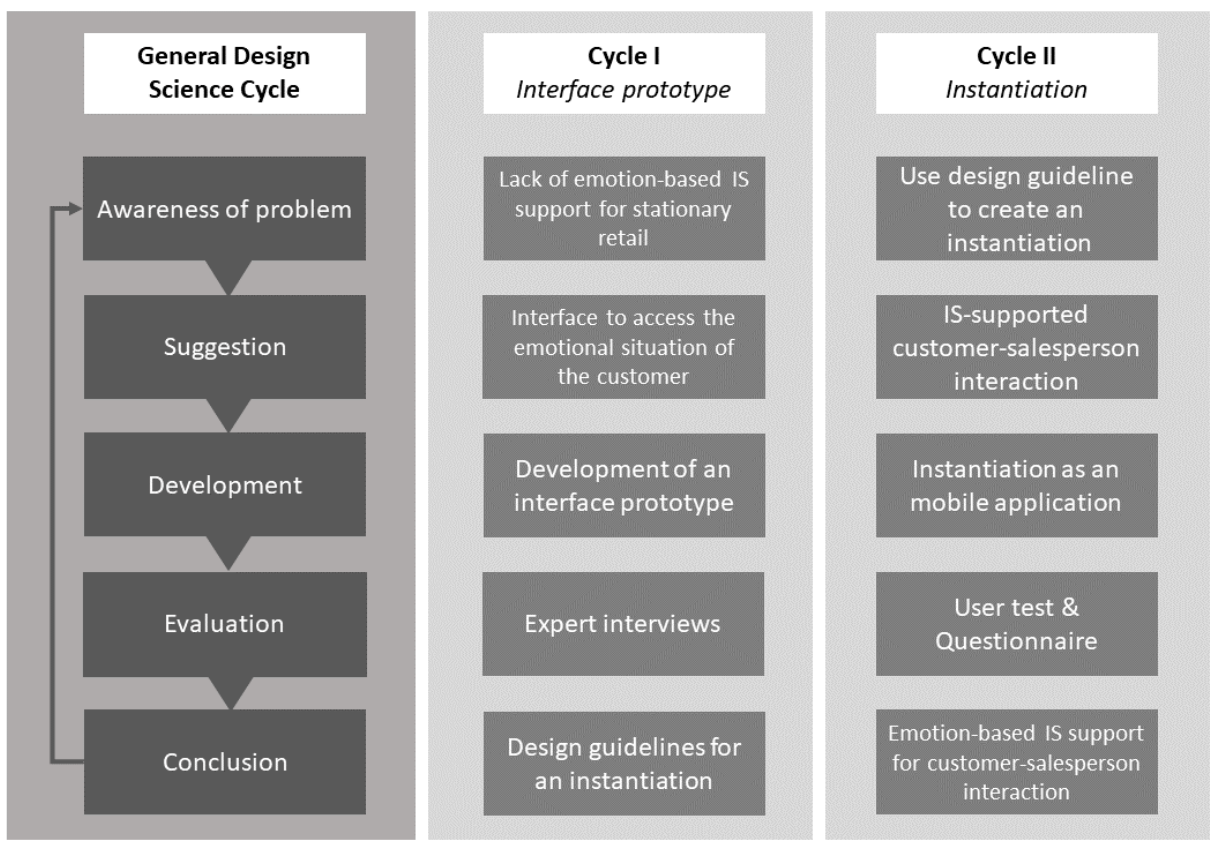

Figure 1: Design Cycles 
[35]. In order to adapt the CMoA for the intended purpose, we modified it in a number of steps. The emotions displayed in the CMoA (see Figure 2a) were first divided into four emotional situations (see Figure $2 \mathrm{~b})$. The situations 1 and 2 represent high arousal situations, which are either negative (angry/frustrated) or positive (excited/happy). Whereas situations 3 and 4 represent situations of low arousal, which can be negative (sad/tired) or positive (pleased/relaxed). The simplified model was finally designed in tiles and thus adapted to a modern design language (see Figure 2c). The resulting interface prototype is strongly oriented towards the typical look of a mobile application. Finally, the four emotional situations were highlighted with colors and one emoticon per tile was assigned $[42,51]$.

\subsection{Interface Evaluation}

An evaluation of the interface prototype was carried out within the context of guideline-based expert interviews. This way we intended to generate specific design knowledge on how to design emotion-based ISs to support the customer-salesperson interaction. We interviewed four experts in total while using the interface prototype as a stimulus. The interface prototype was introduced to the experts as part of a potential application used in stationary retail. The purpose of the application was explained as determining the emotional situation of the customer and transferring this information to the sales personnel. The main criteria for the selection of the experts was that all selected experts had several years of experience in the field of customer-salesperson interaction. In addition, care was taken to ensure that each expert represents a different user perspective, thus generating as many different viewpoints as possible. All experts were recruited via local business networks by e-mail and none of them received any incentives.

Expert 1 (E1) frequently buys both online and offline and was chosen to provide a customer perspective. Expert 2 (E2) is the manager of a stationary retail store and was selected to describe insights from a retailer perspective. Expert 3 (E3), an employee of an industrial company with experience in multi-channel retail, was part of the interview to gain knowledge from an industry point of view. Finally, in order to include a scientific perspective (E4), a university professor with a research focus on retail management was selected. The created interview guide consisted of three categories. The first category contained general questions towards emotions in the stationary retail branch. In the second category, experts were asked to comment on the design of the interface prototype according to its usability, applicability and design. Finally, in category three, questions regarding the added value for both customer and salesperson were asked. The interviews were recorded and subsequently transcribed. The resulting data was analyzed using codes as an efficient datalabeling and data-retrieval method. The usage of the descriptive codes approach enables to describe and summarize a certain unit of qualitative data [54]. Hence, a direct comparison of the experts' statements over all four interviews was possible. The results of the expert interviews are described in the following.

4.2.1. Emotions in Retail. All experts consider the importance of emotions and their influence in stationary retail to be high. Especially in the case of private purchases, according to E3, emotions are always a crucial factor. According to E2, "relaxed" is the most important and desirable emotional situation in stationary retail: "Many of our customers say that they come to us because it's just so relaxed". E1 criticizes that there is a lack of empathy in the purchasing process. E3 supports this statement by explaining that customer emotions are not given sufficient attention. Both E1 and E2 claim that emotions can already be recognized by the way someone enters the store. However, E2 also points out that even after years of experience the customer's emotional situation can be misjudged. E3 furthermore describes a situation in which he misinterpreted a customer's emotion, which led to an unpleasant

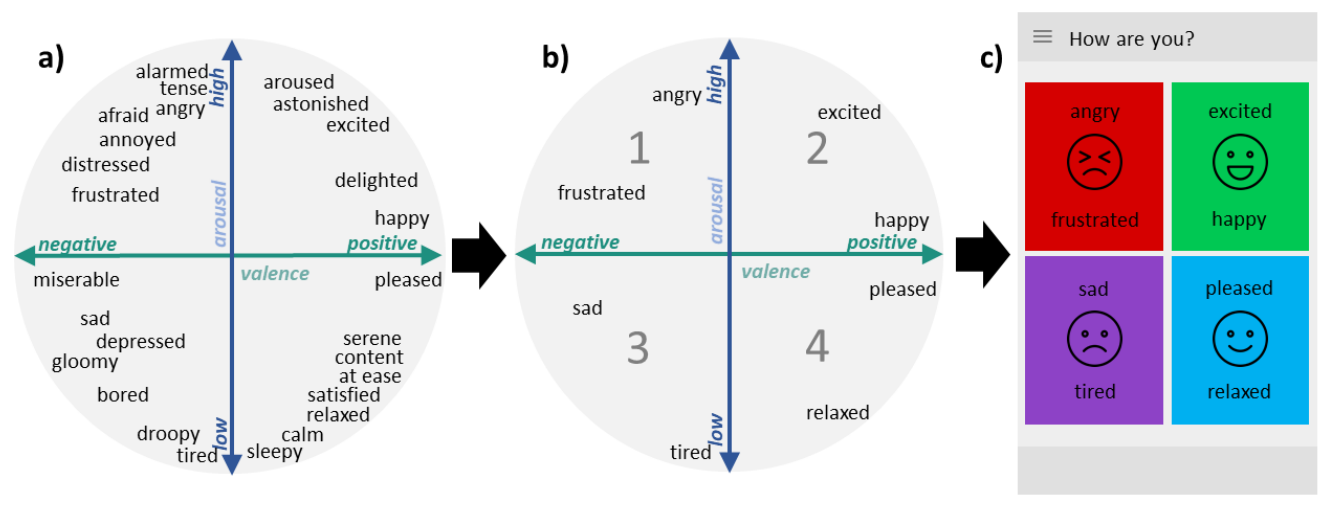

Figure 2: Interface prototype development 
interaction. These statements are in line with the literature regarding the influence of emotions in retail $[12,17]$, the outcomes of positives emotions [59, 72] as well as the crucial part of the right assessment of the emotional situation of the customer [49, 50]. In summary, the expert's statements on emotions in retail can be formulated into two design guidelines (DG):

- DG 1: Enable the customer to enter his/her emotional situation

- DG 2: Enable the sales personal with information regarding the emotional situation of the customer

4.2.2. Look and Feel. Despite the diversity of experts, all of them rated the interface as "simple and clear". In addition, the colors and emoticons were positively received by all experts. E2 strongly agrees with the selection of colors: "Green is always a very positive color, you are happy... Red of course, aggression, angry, please leave me alone”. E4 furthermore mentions that the simple and mobile layout of the interface prototype offers a good usability and makes it suitable for the use in stationary retail. This statement can be linked to the importance of simplicity in mobile user interfaces and the value opportunity that mobile ISs can offer in stationary retail $[34,44]$. Furthermore, the use of emoticons as an intuitive scale [51] as well as the connection between emotions and color [42] can be supported by literature. In summary, the statements of the expert regarding the look and feel of the interface prototype are aggregated into four design guidelines:

- DG 3: Create a mobile interface to secure suitability in the field of application

- DG 4: Create a simple interface to secure suitability in the field of application

- DG 5: Use colors to indicate different emotional situations

- DG 6: Use emoticons to indicate different emotional situations

4.2.3. Added Value. According to E1 and E3, the interface prototype offers added value to stationary retail. E3 sees the interface as a possible way to give customer emotions the attention that is urgently needed in stationary retail. E1 further explains that this targeted customer advice might help stationary retail to keep up with the online world. This claim can be supported by literature regarding customer-centric IS support in stationary retail $[34,38]$. In contrast to this, E4 feels unable to see a value of the interface prototype. This is mainly because of difficulties in the reliable capturing of customer emotions. In fact, the chosen measuringmethod can lead to inaccuracy based on cognitive bias [64]. E2 claims that the presented interface prototype provides value especially for younger and less experienced sales personnel, who often has problems assessing the emotional situation of the customer.

The key findings of the expert interviews are summarized in Table 1. In conclusion, the interviews support the current literature that underlines the importance of customer emotions in the context of stationary retail. The correct assessment of emotions can be difficult and misinterpretation can lead to an unpleasant customer-salesperson interaction. To address this, we were able to design an interface prototype that is perceived as simple and clear in its task to capture the customer's emotional situation. Furthermore, the CMoA presented itself as a suitable foundation for this field of application. The design knowledge gained was specified in six design guidelines. These guidelines will be transferred to the second design cycle in which we develop and evaluate an instantiation in form of a mobile application.

Table 1: Expert interview results

\begin{tabular}{|c|c|c|c|}
\hline $\begin{array}{l}\text { Interview } \\
\text { Guide } \\
\text { Category }\end{array}$ & $\begin{array}{l}\text { Summarized } \\
\text { Statements }\end{array}$ & Experts & $\begin{array}{l}\text { Supporting } \\
\text { Literature }\end{array}$ \\
\hline \multirow{2}{*}{$\begin{array}{l}\text { Emotions } \\
\text { in Retail }\end{array}$} & $\begin{array}{l}\text { Emotions have a } \\
\text { strong influence }\end{array}$ & $\begin{array}{l}\text { E1, E2, } \\
\text { E3, E4 }\end{array}$ & {$[12,17]$} \\
\hline & $\begin{array}{c}\text { The correct } \\
\text { assessment of } \\
\text { emotions is difficult }\end{array}$ & E2, E3 & {$[49,50]$} \\
\hline \multirow{3}{*}{$\begin{array}{l}\text { Look and } \\
\text { Feel }\end{array}$} & $\begin{array}{l}\text { The interface is } \\
\text { simple and clear }\end{array}$ & $\begin{array}{l}\text { E1, E2, } \\
\text { E3, E4 }\end{array}$ & [44] \\
\hline & $\begin{array}{l}\text { The chosen colors } \\
\text { and emoticons are } \\
\text { helpful }\end{array}$ & $\begin{array}{l}\text { E1, E3, } \\
\text { E4 }\end{array}$ & {$[42,51]$} \\
\hline & $\begin{array}{l}\text { The interface is } \\
\text { suitable for the use } \\
\text { in a retail } \\
\text { environment }\end{array}$ & E2, E4 & [34] \\
\hline \multirow{2}{*}{$\begin{array}{l}\text { Added } \\
\text { Value }\end{array}$} & $\begin{array}{l}\text { The interface } \\
\text { provides value }\end{array}$ & $\begin{array}{c}\text { E1, E2, } \\
\text { E3 }\end{array}$ & {$[34,38]$} \\
\hline & $\begin{array}{c}\text { The interface } \\
\text { provides no value }\end{array}$ & $\mathrm{E} 4$ & [64] \\
\hline
\end{tabular}

\section{Instantiation (Cycle 2)}

\subsection{Development of the Instantiation}

Our overall research goal is an emotion-based IS to support the customer-salesperson interaction. Therefore, in this cycle, the design guidelines from cycle 1 are used to create an instantiation in form of a mobile application (DG 3). The results of cycle 1 showed that the customer needs a possibility to enter his or her emotional situation, whereas the sales personal needs a way to receive this information (DG 1/DG 2). The look of the instantiation is strongly oriented on the design of the interface prototype but offers two views: 
The customer view (see Figure 3 bottom left) and the salesperson view (see Figure 3 bottom right). In the customer view, the customer enters his or her emotional situation via self-assessment by choosing between the four emotional situations that are based on the CMoA (DG 4). The color design of the emotional situations corresponds to the interface prototype (DG 5). The emoticons on the other hand were removed and added as a pop-up instead. This way, the design is simpler and the customer has the certainty that the emotional situation was successfully entered (DG 6). Afterwards, the customer's emotional situation is transferred to the sales personnel. While the customer view is realized via a smartphone (see Figure 3 top left), a tablet is used for the salesperson view to display emotional situations of multiple customers (see Figure 3 top right). If a customer situation changes, the sales personnel is notified by a pop-up. To provide this pop-up with recommended actions, a set of previously developed emotion-reaction guidelines was used [52]. Customer profile images, which are created the first time the application is used, make it easy for sales personnel to identify which customer may require further advice. It is also possible to view past emotional situation entries in a timeline as well as analyze the distribution of a customer's emotional history in a pie chart. After a certain period of time, the sales personnel is asked to rate the presented emotion-reaction guideline. This way, a continuous evaluation of the guidelines can take place.

\subsection{Evaluation of the Instantiation}

5.2.1. User test. The instantiation was evaluated as part of a user test. To guide the participants through the instantiation, a test scenario with different tasks was created. During the user test, the participants were asked to put themselves in the role of a customer. The most important selection criterion for the participants was that they use both, online and offline channels for shopping. This ensured that the participants had sufficient experience in using a mobile application and were able to put themselves in the situation of a customer in stationary retail. The participants were recruited via a mailing list at the university. Although the participants took on the role of a customer, they were also able to look at the salespersons' view of the instantiation for which a tablet was used. Thus, the presentation of their own emotional situation entries could be observed. At the beginning of the user test, the research topic and the test devices were explained. Besides the user registration, the test scenario included the selection of different emotional situations. After running the test scenario, the participants were asked to complete a questionnaire.

5.2.2. Questionnaire. The post-test questionnaire divides into three categories. Questions concerning socio-demographic data as well as questions about the purchasing behavior were asked first. A five-point Likert scale was used to determine whether the

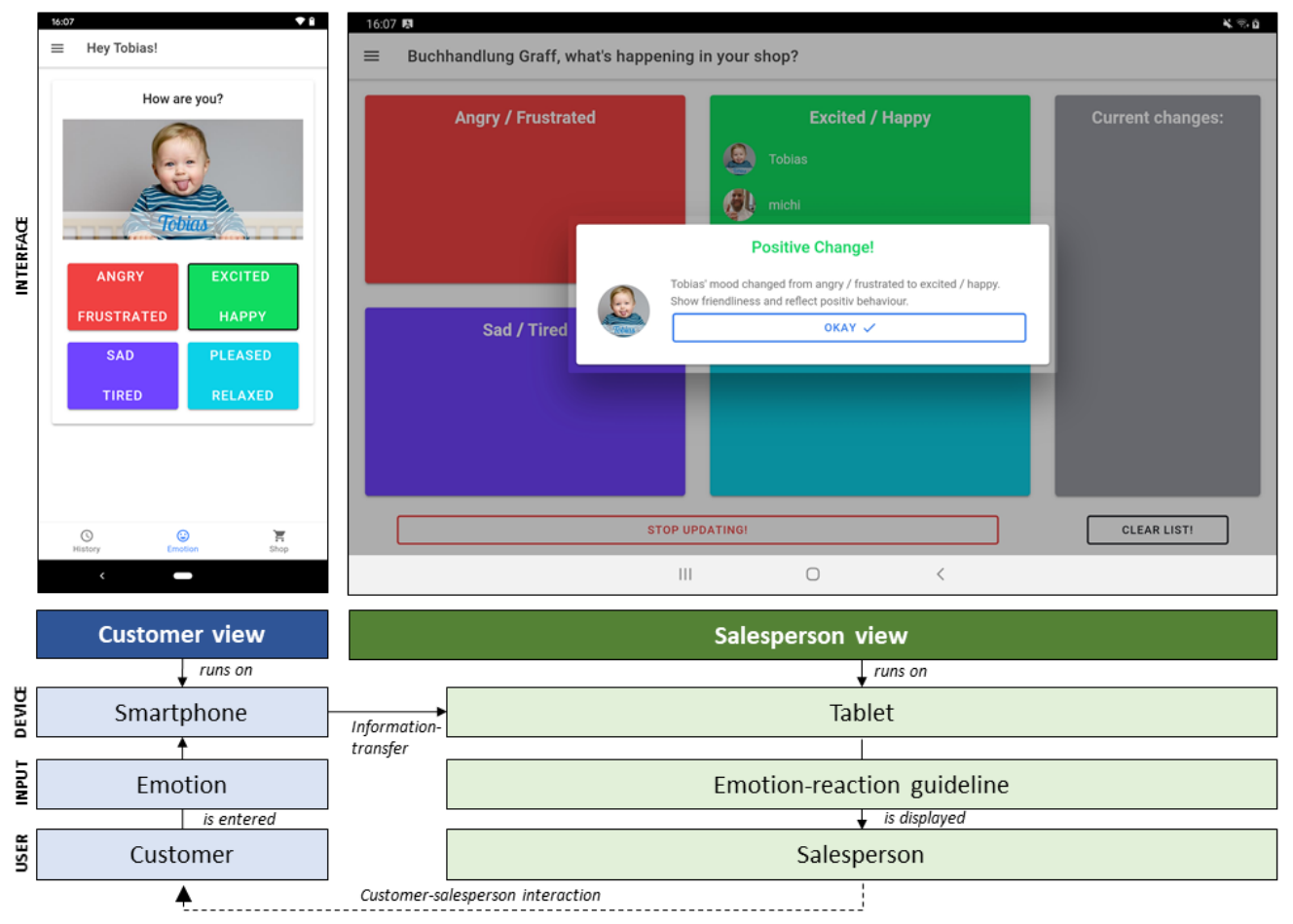

Figure 3: Instantiation 
participants primarily shop online (coded with 1) or in stationary retail (coded with 5). In the second category, we used the System Usability Scale (SUS) to test the usability of our instantiation. The SUS is a wellestablished, highly robust questionnaire for the assessment of perceived usability. It consists of a tenitem, five-point Likert scale [3]. The evaluation of the results follows the procedure given in the literature [11]. Finally, in the third category, different statements concerning the instantiation were presented. In addition to the presentation and selection of emotional situations, general statements about the willingness to communicate one's own emotional situation were formulated. The statements were evaluated on a fivepoint Likert scale $(5=$ strongly agree to $1=$ strongly disagree). The questionnaire ends with open-ended questions regarding missing features of the instantiation.

5.2.3. Results. 17 subjects, aged between 24 and 50 $(\mathrm{M}=29)$, participated in the test, of which 10 were male and 7 female. 11 participants prefer to shop online, 4 participants use both online and stationary retail and 2 participants prefer to shop in stationary retail.

The evaluation of the SUS results in a SUS score with a value between 0 and 100. Our instantiation was able to reach a value of 83.24 [11]. According to the SUS score classification proposed by Bangor et al. (2009), which adds an adjective-based scale [4], the usability of our instantiation can be rated as good to almost excellent.

The results of the third questionnaire category are presented in Table 2. The participants predominantly approved the selection of emotions (statement 1), the color allocation (statement 2) as well as the presentation of the salesperson's view (statement 5). The slightly lower rating of statement 1 might be an indication that additional emotional situations are necessary. In addition, 13 of the 17 participants agreed with the statement that they are willing to share their emotional state with the salesperson to improve the shopping experience (statement 3). Whether an automated or a manual transmission of the emotional situation is preferred lead to inconclusive test results (statement 4). The average rating and the deviation from the mean value of this statement make further investigations necessary.

The review of the open-ended questions revealed additional features that the participants would like to see. Participants 4, 9 and 11 suggested an automated emotion-recognition to enhance the instantiation. Furthermore, two participants mentioned that they miss certain emotional situations. Participant 12 is of the opinion that annoyed should be added to the instantiation, while participant 5 missed stressed as a selectable option. It is worth mentioning that stressed is not an emotion that can be found in the CMoA. Nevertheless, stress is a situation of the human body that is related with negative emotions like anger or anxiety [18]. The emotional situation, annoyed, mentioned by participant 12 can be assigned to emotion-situation 1 (angry/frustrated) (see Figure 2). User tests with a larger sample size should be carried out before the instantiation is modified to reveal further possibly missing emotional situations. Finally, participant 17 would like to add own emotional situations in case none of the emotional situations are fitting.

Table 2: Results of the statements

\begin{tabular}{|l|l|l|l|}
\hline No. & Statement & $\mathrm{M}$ & SD \\
\hline 1 & $\begin{array}{l}\text { The selection of four emotional } \\
\text { situations is sufficient }\end{array}$ & 3.94 & 1.00 \\
\hline 2 & $\begin{array}{l}\text { The colour allocation of the } \\
\text { emotional situations is } \\
\text { appropriate }\end{array}$ & $\begin{array}{l}\text { I am willing to share my } \\
\text { emotional situation with the } \\
\text { salesperson to improve my } \\
\text { shopping experience }\end{array}$ & 0.68 \\
\hline 4 & $\begin{array}{l}\text { I prefer a manual transfer of my } \\
\text { emotional situations over an } \\
\text { automated transfer (e.g. via } \\
\text { camera/smartwatch) }\end{array}$ & 0.97 \\
\hline 5 & $\begin{array}{l}\text { I agree with the presentation of } \\
\text { the emotional situations on the } \\
\text { salesperson's view }\end{array}$ & 1.50 \\
\hline & \multicolumn{4}{|l|}{0.49} \\
\hline
\end{tabular}

\section{Discussion}

In this article, we address the research question: How should an emotion-based IS be designed to support customer-salesperson interaction? In the first designcycle, an interface prototype that was based on the CMoA was developed and evaluated using expertinterviews. The interviews confirmed the importance of customer emotions as well as the difficulty of the correct assessment of emotions. Especially younger and less experienced sales personnel might therefore benefit from an emotion-based IS. All experts described the interface prototype as simple and clear. Design elements like the colors and emoticons were rated positively. In summary, the results of the first design-cycle are confirmed by literature regarding the importance of customer emotions but also showed that a suitable interface in the domain of stationary retail, can be based on the CMoA. Finally, the gained design knowledge of the first design cycle was aggregated into six design guidelines. 
The design guidelines were used to create an instantiation in form of a mobile application with a customer view and a salesperson view. The customer view offers the customer a possibility to enter his or her emotional situation. In comparison, the salesperson view provides the sales personnel with an overview of the current emotional situations of all customers and recommends actions (i.e. the aforementioned emotionreaction guidelines). The instantiation was evaluated as part of a user test. While using the SUS, the results show a good to almost excellent usability. The evaluation of the statements revealed that the participants are mainly satisfied with the provided form of self-assessment. However, the review of the open-ended questions showed two examples of emotional situations that can only partially be represented by the instantiation. The question of sharing emotions to improve the interaction between customers and sales personnel met with high approval. The participants also agreed with the presentation of the information on the salesperson view. Whether an automated transmission of the emotional situation or self-assessment is the more popular choice of measurement, stays inconclusive. Both the high standard deviation and the results from the open-ended questions show potential for further development of the instantiation with regard to other measurement options (see section 2.2).

Overall, the evaluation of the two design cycles offer a diverse contribution. First, we could confirm that both the customer and the sales personnel endorse the importance of emotions in retail, described in the literature. Furthermore, the design of an IS in form of a mobile application can offer a suitable way to support the interaction between customers and sales personnel. The two instantiations show that the CMoA is a promising basis for the design of an interface. The distinction between the four emotional situations, the assignment of colors per emotional situations as well as the use of emoticons could be identified as important design elements. Finally, it has been shown that customers are willing to share their emotional situation using a mobile application to improve the interaction in stationary retail.

However, this study also has limitations on different levels that need to be addressed in further research. Both the interface prototype and the instantiation rely on the self-assessment of the customer. As stated by E4 (see section 4.2.3.), the chosen measurement method may lead to inaccuracies caused by cognitive bias [64]. To counteract this and add a more objective measurement method, an additional emotion measurement based on biofeedback will be implemented in a later stage of development. After the initial input of the emotion by self-assessment, this would provide the possibility to detect changes automatically in the emotional situation of the customer [71]. This type of measurement was also suggested by some participants of the user test in the second design cycle. A further limitation is based on the fact that the sample size in both cycles is relatively small, which allows only limited generalization of the results. For the next research steps, a larger number of sales personnel and customers who primarily shop in stationary retail trade should be included.

\section{Conclusion}

With the overarching goal of supporting stationary retail in the digital transformation, this paper focused on its existing strengths: customer advisory and social interaction. To ensure that the customer has a pleasant and valuable visit, we propose an emotion-based IS as a new solution for an improved interaction between customers and sales personnel. Essential for this support is a set of emotion-reaction guidelines that serve the sales personnel to react appropriately. Further and especially interdisciplinary research needs to address the aspect of how to react to certain customer emotions and construct different emotion-reaction guidelines for a variety of contexts (e.g. different retailer branches), as these guidelines are an important part of the emotionbased IS. Additional instantiations and evaluations should be conducted to validate our design guidelines in order to refine and extent them. In the process, various design elements will be compared in A/B testing [6]. According to the DSR methodology, applying the artifact to a case study is one of the recommended methods of demonstration [61]. Consequently, the instantiation is evaluated within a field test under realistic conditions. The local stationary retail with its variety of small- and medium-sized shops offers a promising target for this. Hereby we have to answer the question whether the interaction between customers and sales personnel can actually be supported and whether it is possible to offer stationary retail the urgently needed reinforcement.

\section{References}

[1] Agnihotri, A., "Can Brick-and-Mortar Retailers Successfully Become Multichannel Retailers?", Journal of Marketing Channels 22(1), 2015, pp. 62-73.

[2] Bagozzi, R.P., M. Gopinath, and P.U. Nyer, "The Role of Emotions in Marketing", Journal of the Academy of Marketing Science 27(2), 1999, pp. 184-206.

[3] Bangor, A., P. Kortum, and J. Miller, "An Empirical Evaluation of the System Usability Scale", International Journal of Human-Computer Interaction 24(6), 2008, pp. 574-594. 
[4] Bangor, A., P. Kortum, and J. Miller, "Determining What Individual SUS Scores Mean: Adding an Adjective Rating Scale", Journal of Usability Studies 4(3), 2009, pp. 114-123. [5] Beaudry, and Pinsonneault, "The Other Side of Acceptance: Studying the Direct and Indirect Effects of Emotions on Information Technology Use", MIS Quarterly 34(4), 2010, pp. 689.

[6] Betella, A., and P.F.M.J. Verschure, "The Affective Slider: A Digital Self-Assessment Scale for the Measurement of Human Emotions", PLoS ONE 11(2), 2016.

[7] BigCommerce, "U.S. online shopping preference by age group", Statista, 2017 https://www.statista.com/statistics/242512/online-retailvisitors-in-the-us-by-age-group/

[8] Blazquez, M., "Fashion Shopping in Multichannel Retail: The Role of Technology in Enhancing the Customer Experience", International Journal of Electronic Commerce 18, 2014, pp. 97-116.

[9] Bradley, M.M., and P.J. Lang, "Measuring emotion: The self-assessment manikin and the semantic differential", Journal of Behavior Therapy and Experimental Psychiatry 25(1), 1994, pp. 49-59.

[10] Brave, S., and C. Nass, "Emotion in Human-Computer Interaction", In J.A. Jacko and A. Sears, eds., The Humancomputer Interaction Handbook. L. Erlbaum Associates Inc., Hillsdale, NJ, USA, 2003, 81-96.

[11] Brooke, J., "SUS: a 'quick and dirty' usability scale", In P.W. Jordan, B. Thomas, B.A. Weerdmeester and A.L. McClelland, eds., Usability Evaluation in Industry. London. Taylor and Francis, London, 1996.

[12] Burns, D.J., and L. Neisner, "Customer satisfaction in a retail setting: The contribution of emotion", International Journal of Retail \& Distribution Management 34(1), 2006, pp. 49-66.

[13] Cabanac, M., "What is emotion?", Behavioural Processes 60(2), 2002, pp. 69-83.

[14] Delmond, M.-H., F. Coelho, A. Keravel, and R. Mahl, "How Information Systems Enable Digital Transformation: A Focus on Business Models and Value Co-Production", IUP Journal Of Business Strategy 14(3), 2017, pp. 7-40.

[15] Deng, and Poole, "Affect in Web Interfaces: A Study of the Impacts of Web Page Visual Complexity and Order", MIS Quarterly 34(4), 2010, pp. 711.

[16] Doherty, N.F., and F. Ellis-Chadwick, "Evaluating the role of electronic commerce in transforming the retail sector", The International Review of Retail, Distribution and Consumer Research 20(4), 2010, pp. 375-378.

[17] van Dolen, W., K. de Ruyter, and J. Lemmink, "An empirical assessment of the influence of customer emotions and contact employee performance on encounter and relationship satisfaction", Journal of Business Research 57(4), 2004, pp. 437-444.

[18] Du, J., J. Huang, Y. An, and W. Xu, "The Relationship between stress and negative emotion: The Mediating role of rumination", Clinical Research and Trials 4, 2018, pp. 1-5.

[19] Ekkekakis, P., The measurement of affect, mood, and emotion: A guide for health-behavioral research, Cambridge University Press, New York, NY, US, 2013.

[20] Faullant, R., Psychologische Determinanten der Kundenzufriedenheit: der Einfluss von Emotionen und Persönlichkeit, Dt. Univ.-Verl, Wiesbaden, 2007.
[21] Fulgoni, G.M., "The Rise of the Digital Omnivore: What It Means for Advertisers, Publishers, and App Developers", Journal of Advertising Research 55(2), 2015, pp. 115-119.

[22] Funches, V., "The consumer anger phenomena: causes and consequences", Journal of Services Marketing 25(6), 2011, pp. 420-428.

[23] Fyrberg, A., and R. Jüriado, "What about interaction?: Networks and brands as integrators within service-dominant logic", Journal of Service Management 20(4), 2009, pp. 420432.

[24] Geiger, M., S. Robra-Bissantz, and M. Meyer, "Focus on Interaction: Applying Service-Centric Theories in IS", Proceedings of 33rd Bled eConference Enabling Technology for Sustainable Society, (2020), 665-672.

[25] Gimpel, H., and M. Röglinger, Digital Transformation: Changes and Chances - Insights based on an Empirical Study, Project Group Business and Information Systems Engineering (BISE) of the Fraunhofer Institute for Applied Information Technology FIT, Augsburg/Bayreuth, 2015.

[26] Grönroos, C., "An Applied Service Marketing Theory”, European Journal of Marketing 16(7), 1993, pp. 30-41.

[27] Grönroos, C., "Adopting a service logic for marketing”, Marketing Theory 6(3), 2006, pp. 317-333.

[28] Grönroos, C., "A service perspective on business relationships: The value creation, interaction and marketing interface", Industrial Marketing Management 40(2), 2011, pp. 240-247.

[29] Grönroos, C., and P. Voima, "Critical service logic: making sense of value creation and co-creation", Journal of the Academy of Marketing Science 41(2), 2013, pp. 133-150. [30] Groth, M., and A. Grandey, "From bad to worse: Negative exchange spirals in employee-customer service interactions", Organizational Psychology Review 2(3), 2012, pp. 208-233.

[31] Gutek, B.A., A.D. Bhappu, M.A. Liao-Troth, and B. Cherry, "Distinguishing between service relationships and encounters.", Journal of Applied Psychology 84(2), 1999, pp. $218-233$

[32] Hagberg, J., M. Sundstrom, and N. Egels-Zandén, “The digitalization of retailing: an exploratory framework", International Journal of Retail \& Distribution Management 44(7), 2016, pp. 694-712.

[33] Handelsverband Deutschland (HDE), Online-Monitor 2019, Handelsverband Deutschland (HDE), Berlin, 2019.

[34] Härtfelder, J., and A. Winkelmann, "Opportunities and Challenges for Local Retailing in an Environment Dominated by Mobile Internet Devices - Literature Review and Gap Analysis", Proceedings Multikonferenz Wirtschaftsinformatik, (2016), 33-44.

[35] Helmholz, P., M. Meyer, and S. Robra-Bissantz, "Feel the Moosic: Emotion-based Music Selection and Recommendation", Proceedings of 32th Bled eConference Humanizing Technology for a Sustainable Society, (2019), 719-743.

[36] Hevner, A., S.T. March, J. Park, and S. Ram, "Design science research in information systems", MIS quarterly 28(1), 2004, pp. 75-105.

[37] Heyes, A., and S. Kapur, "Angry customers, e-word-ofmouth and incentives for quality provision", Journal of Economic Behavior \& Organization 84(3), 2012, pp. 813828. 
[38] Hosseini, S., M. Röglinger, and F. Schmied, "OmniChannel Retail Capabilities: An Information Systems Perspective", 38th International Conference on Information Systems (ICIS), (2017).

[39] Iivari, J., "Distinguishing and contrasting two strategies for design science research", European Journal of Information Systems 24(1), 2015, pp. 107-115.

[40] Izard, C.E., Human Emotions, Plenum Press, New York, 1977.

[41] Kahneman, D., "Maps of Bounded Rationality: Psychology for Behavioral Economics", American Economic Review 93(5), 2003, pp. 1449-1475.

[42] Kaya, N., and H.H. Epps, "Relationship between color and emotion: A study of college students", College Student Journal 38, 2004, pp. 396-405.

[43] Kleinginna, P.R., and A.M. Kleinginna, "A categorized list of emotion definitions, with suggestions for a consensual definition", Motivation and Emotion 5(4), 1981, pp. 345-379. [44] Lee, D., J. Moon, Y.J. Kim, and M.Y. Yi, “Antecedents and consequences of mobile phone usability: Linking simplicity and interactivity to satisfaction, trust, and brand loyalty", Information \& Management 52(3), 2015, pp. 295304.

[45] Lee, S., and A. Dubinsky, "Influence of salesperson characteristics and customer emotion on retail dyadic relationships", The International Review of Retail, Distribution and Consumer Research 13(1), 2003, pp. 21-36. [46] Lerner, J.S., D.A. Small, and G. Loewenstein, "Heart Strings and Purse Strings. Carryover Effects of Emotions on Economic Decisions", Psychological Science 15(5), 2004, pp. 337-341.

[47] Lövheim, H., "A new three-dimensional model for emotions and monoamine neurotransmitters", Medical Hypotheses 78(2), 2012, pp. 341-348.

[48] Martin, D., M. O’Neill, S. Hubbard, and A. Palmer, "The role of emotion in explaining consumer satisfaction and future behavioural intention", Journal of Services Marketing 22(3), 2008, pp. 224-236.

[49] Mattila, A.S., and C.A. Enz, "The Role of Emotions in Service Encounters", Journal of Service Research 4(4), 2002, pp. 268-277.

[50] Menon, K., and L. Dubé, "Ensuring greater satisfaction by engineering salesperson response to customer emotions", Journal of Retailing 76(3), 2000, pp. 285-307.

[51] Meschtscherjakov, A., A. Weiss, and T. Scherndl, "Utilizing Emoticons on Mobile Devices within ESM studies to Measure Emotions in the Field", Proceedings of MME in conjunction with MobileHCI 2009, (2009), 3361-3366.

[52] Meyer, M., P. Helmholz, F. Temps, and S. RobraBissantz, "(How) Can I help you? Emotion-ReactionGuidelines for the Stationary Retail", FDIBA Conference Proceedings, (2019), 89-92.

[53] Mian, S.Q., and H. Oinas-Kukkonen, "An Analysis of Previous Information Systems Research on Emotions", Fourth International Workshop on Behavior Change Support Systems, 2016, pp. 36-55.

[54] Miles, M.B., A.M. Huberman, and J. Saldaña, Qualitative data analysis: a methods sourcebook, 2014.

[55] National Retail Federation, Consumer View Summer 2019, 2019.
[56] Normann, R., Reframing Business: When the Map Changes the Landscape, John Wiley \& Sons, Chichester, New Sussex, 2001.

[57] Oh, L.-B., and H.-H. Teo, "Consumer Value Co-creation in a Hybrid Commerce Service-Delivery System", International Journal of Electronic Commerce 14(3), 2010, pp. 35-62.

[58] Otto, J.R., and Q.B. Chung, "A Framework for CyberEnhanced Retailing: Integrating E-Commerce Retailing with Brick-and-Mortar Retailing", Electronic Markets 10(3), 2000, pp. 185-191.

[59] Ou, Y.-C., and P.C. Verhoef, "The impact of positive and negative emotions on loyalty intentions and their interactions with customer equity drivers", Journal of Business Research 80, 2017, pp. 106-115.

[60] Pantano, E., and P. Migliarese, "Exploiting consumeremployee-retailer interactions in technology-enriched retail environments through a relational lens", Journal of Retailing and Consumer Services 21(6), 2014, pp. 958-965.

[61] Peffers, K., T. Tuunanen, M.A. Rothenberger, and S. Chatterjee, "A Design Science Research Methodology for Information Systems Research", Journal of Management Information Systems 24(3), 2007, pp. 45-77.

[62] Peter, C., and B. Urban, "Emotion in Human-Computer Interaction", In J. Dill, R. Earnshaw, D. Kasik, J. Vince and P.C. Wong, eds., Expanding the Frontiers of Visual Analytics and Visualization. Springer London, London, 2012, 239-262. [63] Plutchik, R., "The Nature of Emotions: Human emotions have deep evolutionary roots, a fact that may explain their complexity and provide tools for clinical practice", American Scientist 89(4), 2001, pp. 344-350.

[64] Poels, K., and S. Dewitte, "How to Capture the Heart? Reviewing 20 Years of Emotion Measurement in Advertising", Journal of Advertising Research 46(1), 2006, pp. 18-37.

[65] Reynolds, K.E., and S.E. Beatty, "A relationship customer typology", Journal of Retailing 75(4), 1999, pp. 509-523.

[66] Russell, J.A., “A circumplex model of affect”, Journal of Personality and Social Psychology 39(6), 1980, pp. 11611178.

[67] Russell, J.A., "Introduction to special section: On defining emotion", Emotion Review 4(4), 2012, pp. 337-337. [68] Spaid, B.I., and D.J. Flint, "The Meaning of Shopping Experiences Augmented By Mobile Internet Devices", The Journal of Marketing Theory and Practice 22(1), 2014, pp. 73-90.

[69] U.S. Department of Commerce, US Census Bureau Monthly \& Annual Retail Trade, 2020.

[70] Vaishnavi, V.K., W. Kuechler, and W. Kuechler, Design Science Research Methods and Patterns: Innovating Information and Communication Technology, 2nd Edition, CRC Press, 2015.

[71] Yamamoto, J., M. Kawazoe, J. Nakazawa, K. Takashio, and H. Tokuda, "MOLMOD: Analysis of Feelings based on Vital Information for Mood Acquisition", IEICE Technical Report (Institute of Electronics, Information and Communication Engineers) 109(131), 2009, pp. 63-68.

[72] Yu, Y., and A. Dean, "The contribution of emotional satisfaction to consumer loyalty", International Journal of Service Industry Management 12(3), 2001, pp. 234-250. 